\title{
Safe Handling of Food and Water in a Hurricane or Related Disaster ${ }^{1}$
}

\section{Ronald H. Schmidt, Keith L. Schneider, Renée Goodrich, Amarat Simonne, and Douglas L. Archer ${ }^{2}$ \\ The following is a summary of general recommendations to protect the safety of food and \\ Emergency Preparation (Before the Storm)} water in the event of a hurricane, flooding, or related natural disaster. These recommendations have been adapted from those developed under National Recommendations for Disaster Food Handling, a multi-state grant involving Cooperative Extension collaborators from Tennessee, Florida, and Missouri as well as the American Red Cross and Tennessee Department of Agriculture. Recommendations have also been included from additional up-to-date sources such as the: Centers for Disease Control and Prevention (CDC), Environmental Protection Agency (EPA), Food and Drug Administration (FDA), Florida Department of Agriculture and Consumer Services (DOACS), Florida Department of Health (DOH), Federal Emergency Management Agency (FEMA), and American Red Cross.
Have a Plan

As hurricane season approaches, a written plan should be developed for your household. The plan should be reviewed frequently with all members of the household.

\section{What to Include in the Plan}

At a minimum, the plan should include the following:

\section{Essential item check list}

Make a list of items considered essential in the event of evacuation (e.g., special medications, foods for those on special diet), and collect these items in one location.

1. This document is FSHN05-20, one of a series of the Food Science and Human Nutrition Department, Florida Cooperative Extension Service, Institute of Food and Agricultural Sciences, University of Florida. Original publication date October 2005. Visit the EDIS Web Site at http://edis.ifas.ufl.edu.

2. Ronald H. Schmidt, professor; Keith R. Schneider, assistant professor, both of the Food Science and Human Nutrition Department, Institute of Food and Agricultural Studies, Cooperative Extension Service, University of Florida, Gainesville; Renée M. Goodrich, assistant professor, Food Science and Human Nutrition Department, Citrus Research and Education Center, Institute of Food and Agricultural Studies, Cooperative Extension Service, University of Florida, Lake Alfred, FL 33850; Amy Simonne, assistant professor, Department of Family, Youth and Community Sciences; and Douglas L. Archer, professor, Food Science and Human Nutrition Department, Cooperative Extension Service, Institute of Food and Agricultural Sciences, University of Florida, Gainesville, 32611.

The Institute of Food and Agricultural Sciences (IFAS) is an Equal Opportunity Institution authorized to provide research, educational information and other services only to individuals and institutions that function with non-discrimination with respect to race, creed, color, religion, age, disability, sex, sexual orientation, marital status, national origin, political opinions or affiliations. U.S. Department of Agriculture, Cooperative Extension Service, University of Florida, IFAS, Florida A. \& M. University Cooperative Extension Program, and Boards of County Commissioners Cooperating. Larry Arrington, Dean 


\section{Adequate containers, utensils, and paper goods}

Collect several food grade containers for storing water and food. To make potential evacuation more efficient, these containers should be light weight and easy to carry. Collapsable water containers are available through camping supply stores. Maintain a supply of disposable utensils (e.g., forks, knives, spoons, cups), as well as a manual can opener. Finally, maintain an adequate supply of paper goods (e.g., paper towels, toilet paper). As the supply of clean water may be limited following an evacuation, it is recommended that a supply of sanitary hand wipes be purchased. While these hand wipes do not replace hand washing, they can be used in addition to hand washing.

\section{Disaster supply kit}

Assemble a "kit" (to fit in the trunk of your vehicle) which includes nonperishable food and water (for a minimum of 24 hours) and other disaster supplies. This disaster supply kit should be updated annually.

\section{Refrigerator and freezer}

Organize and prepare the refrigerator and freezer (where time allows) as follows:

- A thermometer should be maintained in the refrigerator at all times and the temperature should be held at $41^{\circ} \mathrm{F}\left(5^{\circ} \mathrm{C}\right)$ or less. However, in preparation for a possible power outage, it is recommended that the temperature controls be set colder than normal;

- Clean the refrigerator and freezer, and examine the gaskets, replacing those that are worn

- Discard old or unnecessary items;

- Take an inventory of food items and post the inventory list in an accessible location;

- Organize the freezer compartment by grouping meat and poultry on one side or on separate trays so that, in the event of thawing, their juices will not contaminate each other or other foods; and

- If the freezer is not full, fill and freeze containers of water to fill the space. This will slow down the temperature increase in the event of a power failure.

\section{Water supplies}

Evaluate the water needs of your family. It is recommended that you maintain at least a two-day supply of water. Allow a sufficient quantity per day for drinking (1 gallon/person), food preparation (one half gallon/person), and hygiene (one half gallon/person). In hot weather, allow more water for drinking ( 2 gallons/day). Commercially bottled water is best if available. If you do not have commercially bottled water, other sources of emergency water may be used. Assess and make a list of potential emergency water supplies available to your household. Some recommendations suggest filling bathtubs with water as a source of water (for non-drinking purposes). Be sure the tub is cleaned thoroughly prior to filling. The toilet tank may also be used as a source of water. These water sources may be used for bathing or shaving without purification provided that care is taken not to swallow the water. However, if water stored in either of these places is to be used for drinking, hand washing, washing fruits and vegetables, dish washing, or cooking, it should be purified (or sanitized) using a recommended procedure as described later (see the section "Water Handling"). In preparation, the following should be purchased and maintained on hand:

- Commercially bottled water (several bottles); and

- Non-scented liquid chlorine bleach (several bottles).

\section{Food supplies}

A sufficient quantity of shelf-stable, non-perishable foods should be maintained on hand. Recommendations include:

- Canned foods such as: vegetables, soups, condensed milk, canned meat, canned fruit and fruit juices, and nuts; 
- Dry foods such as: powdered milk, dried fruit, pasta, rice, instant coffee and tea, cocoa, and crackers;

- Potatoes and other shelf-stable vegetables;

- Ready-to-eat cereals;

- Soft drinks; and

- Other easy-to-prepare or ready-to-eat foods.

A variety of freeze dried food items are also available at camping supply stores. These stores may also stock "self-cooking" food items and other innovations.

It is important that family members maintain their strength during and after the storm. Therefore, be sure to consider nutrition as well as likes and dislikes of family members (especially children) when stocking up on food.

\section{Dry ice}

It is recommended that you locate the supplier of dry ice in your area. Dry ice is not available in all locations.

\section{Evacuation}

If evacuation is required, follow instructions from local agencies and evacuate to the designated evacuation site. Take essential items with you.

\section{Assessing In-Home Damage and Needs (After the Storm)}

The following is a list of recommended areas to consider when assessing damage and emergency needs, either following the storm or when returning home from an evacuation:

Structural and Related Damage

\section{Electrical and structural systems}

Use care in examining these services and systems for damage. Consult a professional as needed.

\section{Flooding or rain intrusion}

If flooding has occurred, inspect the area for hazardous chemical containers that may have been buried, been moved, or have leaked. Flooding may also carry silt, raw sewage, oil, and other chemicals into your house. Leaking from structural damage to the roof may also cause contamination of food and food contact surfaces.

\section{Water supply and plumbing}

Examine (or have a professional examine) your plumbing for damage. Consult local authorities regarding the potential safety of the water supply or have the water supply tested (especially wells, cisterns, or springs) for safe use. If the municipal water supply is considered contaminated or at risk, the local Health Department will usually issue a Boil Water Advisory via the news media.

\section{Emergency Provisions}

\section{Emergency water}

Examine your emergency water supplies to be sure that they have not become contaminated. Any water from these emergency sources should be decontaminated or purified using one of the procedures described in the "Water Handling" section.

\section{Food}

Assess whether any food items have become contaminated or whether perishable foods have been held at an unsafe temperature due to a power outage. See the "Food Handling" section below for further procedures.

\section{Food utensils and other non-food items}

Assess whether there has been contamination of food utensils, paper or plastic items, medicines, or any other items which will come in contact with food or the mouth. 


\section{Emergency Procedures}

\section{Water Handling}

If the water supply is contaminated, or if you are under a Boil Water Advisory, all water to be used for drinking, hand washing, washing fruits and vegetables, dish washing, or cooking, must be purified (e.g., disinfected or sanitized). Certain precautions must be taken when handling water. They are outlined below.

\section{Purifying Water}

The most common methods for purifying water include: boiling, using commercially available purification kits, or using common household chemicals. If performed according to recommended procedures and conditions, these water purification methods adequately remove unwanted infectious bacteria or other biological contaminants from most water. It should be noted, however, that none of these methods will purify water that is contaminated with hazardous chemicals. In addition, presence of suspended soils and other contaminants in water decrease the effectiveness of water purification or disinfection. Prior to purification, water with suspended soils should be allowed to sit for sufficient time to allow settling of the impurities. It should then be decanted, and filtered through several layers of cloth or paper towels. If the water is cloudy after these treatments, longer boiling times or high chemical concentrations are usually recommended.

The recommended water purification procedures are as follows:

\section{Boiling}

This is a relatively easy water purification technique to perform. However, this option may not be available when the power is out. If boiling is used, the water should be brought to a rolling boil for at least one (1) minute and allowed to cool before dispensing into a clean, sanitized, tightly capped container. Water that is cloudy should be boiled longer (3-5 minutes). If your area is under a Boil Water Advisory, follow the health department's recommendations, which may involve longer boiling times if more heat resistant parasites and certain protozoa (e.g., Giardia, Cryptosporidium) are suspected as contaminants. In general, boiling is more effective at killing these pathogens than most chemical methods.

\section{Water purification kits}

Commercial water purification kits are available from pharmacies, and camping and outdoor supply stores. These range from chemical disinfectants (liquid or pellets) to water filtration devices. These kits are generally designed for small quantities of water and, thus, may not be practical for large quantities. If a purification kit is used, closely follow the recommended procedures on the label.

\section{Water purification using common household chemicals}

The most common chemical water purification in the home is done with either chlorine bleach or iodine. If used properly, the water will not be toxic after the use of these chemicals, but may have an odor or taste.

\section{A. Household chemicals used}

1. Chlorine Bleach. There are many different types of bleach on the market. Read the label to be sure that sodium hypochlorite is the only active ingredient. Do not use bleach solutions that contain detergents or other chemical components (e.g., scented bleach). If the container has a label warning "not for personal use" it should not be used. Fresh, unopened, liquid laundry bleach contains $5.25 \%$ sodium hypochlorite. However, a bottle of bleach which has been open for an extended period of time may lose some of its strength, especially if the container is only partially full.

2. Iodine. Iodine tablets and liquid iodine (Tincture of Iodine) can also be used to purify water. Again, read the label for recommended procedures. Tincture of Iodine usually contains $2.0 \%$ U.S.P. iodine. However, there is some variation in this product. In general, iodine has the disadvantage (compared to chlorine) in that it is not as effective over a wide range of pathogens and it imparts taste and a brown tint 
to the water. Thus, it should be used only when chlorine is not available.

\section{B. Purification Procedure}

1. Add the recommended level of the chemical (Table 1) using a clean, uncontaminated medicine dropper or suitable utensil.The following conversions may be helpful in determining the correct amount:

$$
\begin{aligned}
& 8 \text { drops }=1 / 8 \text { teaspoon } \\
& 16 \text { drops }=1 / 4 \text { teaspoon } \\
& 32 \text { drops }=1 / 2 \text { teaspoon } \\
& 64 \text { drops }=1 \text { teaspoon } \\
& 192 \text { drops }=1 \text { tablespoon } \\
& 384 \text { drops }=2 \text { tablespoons }(1 / 8 \text { cup })
\end{aligned}
$$

3. Stir the chemical thoroughly into the water. If the water does not have a faint chemical smell after the 30 minute waiting period, add another dose and let it sit for an additional 15 minutes.

4. Allow the water to stand for 30 minutes. If the water is cloudy, repeat the procedure.

5. Dispense into a clean, sanitized, and tightly capped container, which has been appropriately labeled to indicate its contents.

Table 1. Recommended concentrations of chlorine bleach or iodine products for water purification.

\begin{tabular}{|c|c|c|c|}
\hline $\begin{array}{c}\text { Volume } \\
\text { of Water } \\
\text { to Be } \\
\text { Purified }\end{array}$ & \multicolumn{3}{|c|}{ Recommended Amount of Chemical } \\
\cline { 2 - 4 } & $\begin{array}{c}\text { Chlorine } \\
\text { (bleach) }\end{array}$ & $\begin{array}{c}\text { lodine } \\
\text { Tablets }\end{array}$ & $\begin{array}{c}\text { Tincture } \\
\text { of lodine } \\
3\end{array}$ \\
\hline $\begin{array}{c}1 \text { quart (1 } \\
\text { liter) } \\
1 / 2 \text { gallon } \\
(2 \text { liter) }\end{array}$ & $\begin{array}{l}8 \text { drops }(1 / 8 \\
\text { teaspoon) }\end{array}$ & 4 tablets & 1 drop \\
\hline $\begin{array}{l}1 \text { gallon (4 } \\
\text { liter) }\end{array}$ & $\begin{array}{l}16 \text { drops } \\
\text { ( } 1 / 4 \text { teaspoon) }\end{array}$ & 8 tablets & 2 drops \\
\hline
\end{tabular}

Table 1. Recommended concentrations of chlorine bleach or iodine products for water purification.

${ }^{1}$ Fresh, unscented laundry bleach containing 5.25\% hypochlorite. If the bleach has been opened for a period of time or is less concentrated, increase the amount added. If the water is cloudy in appearance repeat the procedure.

${ }^{2}$ Dry iodine tablets.

${ }^{3}$ Liquid iodine solution. Label concentration of $2.0 \%$ iodine. If a tincture of iodine is used with a different stated iodine concentration, the usage level may be calculated as follows: $\mathrm{Drops} / \mathrm{gal}=\mathbf{8 0}$ divided by the $\%$ iodine in the concentrated solution.

\section{Storing Water}

Conserve water as much is possible and handle purified water with care. It defeats the purpose of purification to allow the water to be re-contaminated. If stored in a tight container in a cool, dry, dark place, both commercially bottled and purified water are safe for an indefinite time period. However, once opened, it should be used within 2-3 days (or re-purified). Do not store water in direct sunlight, and do not store it next to gasoline, kerosene, pesticides, or similar substances. To improve the taste of stored water, pour it back and forth between two clean containers several times to aerate it prior to use.

\section{Ice Handling}

Freezing does not purify water and just because it is cold does not mean that ice is safe. Therefore, unless there is absolute certainty that ice is free of contamination, it should not be used for drinks, or be in direct contact with food. Any potentially contaminated ice that is melted and used, should be purified as described above.

\section{Dry Ice Handling}

If available, dry ice can be used to maintain frozen foods in the event of a power outage. Use approximately twenty five (25) pounds of dry ice per ten (10) cubic foot of freezer or chest space. The following precautions should be observed when using dry ice:

- Dry ice is much colder than any freezer; it will instantaneously freeze skin. Avoid contact with skin. Use gloves or cloths to prevent skin contact; 
- Only use dry ice in rooms with adequate ventilation, as dry ice emits carbon dioxide gas when thawing. If used in a confined freezer compartment, do not cover vent openings; and

- Do not eat dry ice. It is not for consumption.

\section{Food Handling}

\section{What to Discard}

Carefully evaluate which food to discard. Remember to follow these two adages: it is better to be safe than sorry and when in doubt, throw it out. Discard all food products that may have come in direct contact with flood-waters, may have otherwise become contaminated, or may have been stored at an unsafe temperature.

\section{Follow Good Sanitation Procedures}

When handling food, use appropriate precautions so as not contaminate the food. This includes washing your hands (using clean, purified water) before handling food, and preventing cross contamination of food by avoiding contaminated surfaces or objects. In extreme conditions where the purified or potable water supply is strictly limited, the hands may be washed in non-potable water followed by the use of a hand sanitizer or hand sanitizer wipe in accordance with label recommendations.

\section{Recommended Order of Food Usage}

In general, if there has been a power outage, it is recommended that perishable foods from the refrigerator or pantry be used first. Then use the foods from the freezer, followed by non-perishable food supplies. The following guideline can be used to estimate the approximate time that food may be held at appropriate cold temperatures in:

- Refrigerator: if kept closed, approximately 4 hours;

- Full freezer: if kept closed, approximately 48 hours;
- Half full freezer: if kept closed, approximately 24 hours; and

- Dry ice: 2 to 3 days.

\section{How to Handle Specific Food Categories}

\section{Fresh fruits and vegetables}

If exposed to flood waters, all fresh fruits and vegetables, garden produce, and related fresh foods should be discarded. If contaminated, these foods cannot be adequately cleaned and sanitized.

\section{Refrigerated food}

In general, if there is a power outage, a well insulated freezer or refrigerator will maintain refrigeration or freezing temperatures for several hours, provided that the door is kept closed and only opened as often as necessary. However, it is recommended that you monitor the temperature of the refrigerator periodically. Remember that you cannot rely on appearance or odor to determine whether a food will make you sick. Your only indication of safety is temperature control. If the refrigerator temperature has risen above $41^{\circ} \mathrm{F}$ $\left(5^{\circ} \mathrm{C}\right)$ for two $(2)$ hours or more, discard all perishable foods. If you are returning to the house after an evacuation of several days and the refrigerator is above $41^{\circ} \mathrm{F}(5 \mathrm{C})$ upon your return, discard perishable foods, as you have no indication of the length of time the food has been at an unsafe temperature. A partial list of foods, normally found in a home refrigerator, have been categorized as perishable vs. more stable, less perishable in Table 2. 
Table 2. Partial list categorizing refrigerated food stability.

\begin{tabular}{|l|l|}
\hline \multicolumn{1}{|c|}{ Perishable Foods } & $\begin{array}{l}\text { More Stable, Less } \\
\text { Perishables Food }\end{array}$ \\
\hline Baby formula, opened & Beef Jerky \\
Chicken & Butter/margarine, higher fat \\
Cold cuts & Canned fruits \\
Custard pies & Fruit juices \\
Deli Meats & Hard cheeses \\
Fresh cut fruits and & Jam, jellies or preserves \\
vegetables & made with sugar \\
Hamburger & Ketchup \\
Leftovers & Mayonnaise, commercial \\
Low fat margarine or & Mustard \\
spreads & Peanut butter \\
Meat & Pickles \\
Milk & Steak sauces and related \\
Milk Products & items \\
Poultry & Sterile shelf milk (Brik Pak) \\
Seafood & and beverages, unopened \\
Shredded cheeses & Syrups \\
Soft cheeses & \\
& \\
\hline
\end{tabular}

\section{Frozen food}

Examine frozen food for evidence of thawing. This should be done with care. As above, the rule of thumb of food safety is that food not be above $41^{\circ} \mathrm{F}$ $\left(5^{\circ} \mathrm{C}\right)$ for 2 hours or more. This also applies to frozen foods. Thus, just because the food has thawed does not mean it is unsafe. It is the total time and temperature that it is held at in the unfrozen state. If upon returning from an evacuation, the temperature of the freezer is at $41^{\circ} \mathrm{F}\left(5^{\circ} \mathrm{C}\right)$ or above, and all food has thoroughly thawed, simply discard the food unless you have an accurate indication of how long the food had been under these conditions. However, food that has been thawed and refrozen, due to the power cycling off and on over an extended time period, is more difficult to assess for damage given its time and temperature history. Thus, if you have reason to suspect that the food has been thawed and refrozen over an extended time period, the safest plan is to discard it. If you have reasonable certainty that the temperature in the freezer had not been above $41^{\circ} \mathrm{F}\left(5^{\circ} \mathrm{C}\right)$ for 2 hours or more, the following recommendations can be followed:

A. Partially frozen food (with ice crystals in the center) should be safe. In addition, such food that contains ice crystals may be refrozen (when the power comes back on) without concern.

B. Fully thawed food (no ice crystals) can be consumed, provided that it has not been held for 2 hours or more at $41^{\circ} \mathrm{F}\left(5^{\circ} \mathrm{C}\right)$. Such thawed food may be cooked, then refrozen, provided that it has been held at $41^{\circ} \mathrm{F}\left(5^{\circ} \mathrm{C}\right)$ or less for no more than two (2) days.

\section{Commercially canned and bottled foods}

A. Risk of food contamination. In the event of a flood, canned foods and beverages in metal (including pull top cans) or glass containers run the risk of becoming contaminated if exposed to flood waters. Use extreme care and discard any screw capped bottles, snap-lid cans, and similar containers which have been exposed to flood waters. To sanitize the outside of metal cans prior to opening, remove the labels and follow one of the following procedures:

1. Completely immerse the cans in water and bring the water to a rolling boil for one (1) minute (Caution: Do not boil carbonated beverage containers), allow to cool, remove, and air dry prior to opening; or

2. Completely immerse the cans in clean water (room temperature) containing two (2) teaspoons chlorine bleach per quart of water or three (3) tablespoons chlorine bleach per gallon of water for 15 minutes, remove, and air dry prior to opening.

\section{B. Sanitizing the outside of food containers.}

Tightly sealed metal cans with no evidence of bulging, swelling, seeping, or other damage may be safe for use, provided that the outside of the containers are carefully and thoroughly cleaned with a detergent, and sanitized prior to opening.

\section{Handling and storage of sanitized} containers. Following sanitizing, relabel (using a permanent marker) and store the cans where they will not be recontaminated. As metal cans that have been sanitized may rust, it is imperative that they be used as soon as possible. As an additional precaution, thoroughly cook the food products from these cans. 


\section{Exposure of containers to hazardous}

materials. In an urban or industrial environment with extensive flooding, there is increased risk that the outside of the cans have been exposed to hazardous chemicals. In this case, it is recommended that the cans be discarded.

\section{Home canned foods}

The seals of home canned foods may not be as tight or complete as those on commercially canned food products. Thus, it is generally recommended that if home canned foods have been exposed to flood-waters or otherwise contaminated, they should be discarded.

\section{Dehydrated foods (e.g., dry or powdered)}

Dry foods which have become wet by contact with flood or rain water should be discarded. Other dry foods, if properly stored to avoid contamination, are generally considered safe.

\section{Food Disposal}

Food disposal may be done with normal garbage pickup. However, if garbage pickup is delayed for an extended time period, spoiled and deteriorated food will create a nuisance and pest problem. In this situation, the discarded food may be buried in the ground at a depth of at least one foot.

\section{Food Preparation}

The following tips can be used in cooking and preparing foods:

\section{Cooking Foods}

If the electricity is off, alternative cooking methods may be used (with appropriate caution). Use extreme care when using open flames. Charcoal grills and camp stoves should not be used to cook indoors, but can be used outdoors. Many ready to eat foods (including commercially canned foods) can be eaten without heating or cooking.

\section{Water Use in Food Preparation}

Use purified water or water from a safe source for washing fruits and vegetables, and for diluting concentrated or powdered food products.

\section{Infant Foods}

If possible, use canned or prepared baby formula that requires no added water. Use only purified or safe water for diluting concentrated or powdered formula.

\section{Non-food Items Intended for Food or Mouth Contact}

Paper and plastic items, and items packaged in plastic cannot be adequately cleaned and sanitized. Therefore, all medicines, cosmetics, baby pacifiers, and baby bottle nipples, which may have become contaminated, should be discarded.

\section{Food Utensils and Food Preparation Areas}

\section{What to use and what to discard}

Evaluate all food utensils and food preparation areas that may have become contaminated with flood waters. Discard any potentially contaminated paper or plastic utensils (e.g., picnic type), wooden or plastic cutting boards. All other potentially contaminated food utensils (e.g., pots, pans, glasses, dishes) may be used if properly cleaned and sanatized.

\section{Cleaning and sanitizing food utensils, equipment, and preparation areas}

Food utensils and equipment that will fit in the sink should be washed thoroughly in detergent solution, rinsed in purified or safe water, and sanitized as follows:

A. Completely immerse in clean water and bring it to a rolling boil for 1 minute, allow to cool, remove, and air dry prior to use; or

B. Completely immerse in clean water (room temperature) containing two (2) teaspoons chlorine bleach per quart or three (3) tablespoons chlorine bleach per gallon for 15 minutes, remove, and air dry prior to use. 
Food preparation areas, large food preparation equipment, the inside of refrigerators, and all other food contact surfaces should also be cleaned thoroughly and sanitized using a bleach sanitizing solution (as described above).

\section{References}

1. Bartos, L. 2003. Household Hints \& Help! Your Emergency Water Supply. University of Nebraska Cooperative Extension, Lancaster County. Accessed August 2005. http://Lancaster.unl.edu/home/Articles/2003/ WaterSupply.htm

2. Department of Health and Human Services (DHHS)/Centers for Disease Control and Prevention (CDC). 2005. Key Facts About Hurricane Readiness. Accessed August 2005.

http://www.bt.cdc.gov/disasters/hurricanes/ readiness.asp

3. DHHS/Food and Drug Administration (FDA). 2005. FDA Offers Valuable Food Safety Information for Hurricane Aftermath. Accessed August 2005. http://www.cfsan.fda.gov/ dms/fsdisas.html

4. Disney, G. W. and W. C. Morris. 1998. Final Report. National Recommendations for Disaster Food Handling. University of Tennessee, Agr. Ext. Serv. 94-EFSQ-1-4150.

5. Environmental Protection Agency (EPA). 1993. Emergency Disinfection of Drinking Water. Accessed August 2005. http://www.epa.gov/OGWDW/faq/emerg.html

6. Federal Emergency Management Agency and American Red Cross. 2004. Food and Water in an Emergency. FEMA 477 A5055. Accessed August 2005. http://www.fema.gov/pdf/library/f\&web.pdf

7. Florida Department of Agriculture and Consumer Services. 2005. Boil Water Notice Guidelines. Accessed August 2005. http://www.doacs.state.fl.us/fs/ Boil_Water_Notice_guidelines.pdf

8. Florida Department of Agriculture and Consumer Services. 2005. Hurricane Preparations Safety Tips and Items to Buy. Accessed August 2005. http://www.floridahurricane.net/hurricane-survivalkit.html

9.Florida Department of Agriculture and Consumer Services. 2005. Emergency Food and Water Supplies. Accessed August 2005. http://www.doacs.state.fl.us/fs/emergency.html.

10. Florida Department of Health. 2005. Hurricane Information Index. Accessed August 2005. http://www.doh.state.fl.us/Hurricane/ hurricane2005.html

11. Florida Department of Health. 2005. State of Florida: Family Preparedness Guide. Accessed August 2005. http://www.doh.state.fl.us/Hurricane/documents/ prepareenglish042.pdf

12. Florida Department of Health. 2005. After the Storm: Health Risks and How to Prevent Them. Accessed August 2005. http://www.doh.state.fl.us/Hurricane/documents/ afterstorm_eng.pdf

13. National Disaster Education Coalition. 2004. Talking About Disaster: Guide for Standard Messages. Accessed August 2005. http://www.disastereducation.org/guide.html

14. US Department of Agriculture (USDA)/Food Safety and Inspection Service (FSIS). 2004. Keeping Food Safe During an Emergency. Accessed August 2005. http://www.fsis.usda.gov/Fact_Sheets/ keeping_food_Safe_during_an_emergency/index.asp

15. World Health Organization (WHO). Ensuring Food Safety in the Aftermath of Natural Disasters. Accessed September 2005. http://www.who.int/foodsafety/foodborne_disease/ emergency/en/

16. World Health Organization (WHO)/Food and Agriculture Organization (FAO). 2005.Food Safety in Natural Disasters.Food Safety Authorities Network (INFOSAN) Information Note No. 5/2005 Natural Disasters. Accessed September 2005. http://www.who.int/foodsafety/fs_management/ No_05_NaturalDisasters_Sept05_en.pdf 